\title{
Fouras - Place Carnot
}

\section{Bastien Gissinger}

URL : http://journals.openedition.org/adlfi/3147

ISSN : 2114-0502

Éditeur

Ministère de la culture

Référence électronique

Bastien Gissinger, «Fouras - Place Carnot », ADLFI. Archéologie de la France - Informations [En ligne], Poitou-Charentes, mis en ligne le 01 mars 2009, consulté le 03 mai 2019. URL : http://

journals.openedition.org/adlfi/3147

Ce document a été généré automatiquement le 3 mai 2019.

(c) Ministère de la Culture et de la Communication, CNRS 


\title{
Fouras - Place Carnot
}

\author{
Bastien Gissinger
}

Identifiant de l'opération archéologique : 204952

Date de l'opération : 2009 (EX)

1 Un diagnostic archéologique a été prescrit sur la place Carnot à Fouras, en bordure de mer et jusque devant l'église Saint-Gaudens, sur une superficie de $2650 \mathrm{~m}^{2}$. La présente opération a permis de mettre en évidence, sur les niveaux de sable naturels du Secondaire, une fréquentation du site à partir de la fin du Néolithique ou de l'âge du Bronze. Plusieurs épisodes sableux, au travers de remblais et d'apports éoliens ou maritimes ont remblayé le secteur, probablement naturellement dans un premier temps. Quelques structures, peut-être déjà antiques, attestent de la fréquentation du lieu. Un fossé avait par exemple peut-être une fonction d'enclos, mais on ignore à quelle période exacte. Il était, de même que deux fosses dont la fonction nous échappe, peut-être antique.

2 L'histoire du site est ensuite marquée, à l'est, par l'installation d'une église au XI ${ }^{\mathrm{e}}$ s. et XII s., d'après la datation communément admise. Un cimetière s'ouvrait au-devant, à l'ouest de l'édifice. Il est caractérisé par une forte utilisation, probablement un léger déplacement. Au XIX ${ }^{e}$ s., on inhumait encore sur ces parcelles. Le diagnostic a permis de montrer la présence de sépultures remontant apparemment au XII $\mathrm{e}$., recoupées par des sépultures d'orientation différente, datées sans conteste du XIX $s$. Une médaille de Sainte-Hélène, décoration décernée à seulement dix Fourasiens en 1857 et 1858, a été mise au jour dans une tombe du XIX ${ }^{\mathrm{e}} \mathrm{s}$. Le cimetière fut purgé à la toute fin de ce siècle, après que l'église ait été remplacée par un nouvel édifice.

3 À l'ouest, une redoute participant à la défense de la ville et de la côte fut construite entre la fin du XVII ${ }^{e}$ s. et le début du XIXes., on ignore quand exactement. Elle tomba en désuétude dans la seconde moitié du XIXe $s$. et fut épierrée dans les toutes dernières années du siècle, en même temps que le cimetière fut déplacé et que la ville se transformait en la station balnéaire bien connue qu'elle est toujours (Fouras-les-Bains). 
4 Ce diagnostic a permis d'appréhender l'histoire de l'occupation dans ce secteur archéologiquement mal connu de la ville.

5 (Fig. $\mathrm{n}^{\circ} 1$ : Vue d'une portion de l'élévation du mur de la redoute moderne et de sa tranchée de fondation)

6 GISSINGER Bastien

\section{ANNEXES}

Fig. $\mathrm{n}^{\circ} 1$ : Vue d'une portion de l'élévation du mur de la redoute moderne et de sa tranchée de fondation

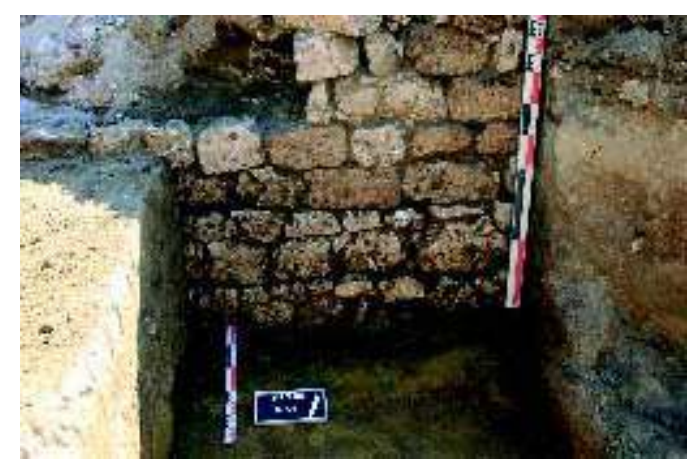

Auteur(s) : Labastie, E. Crédits : Labastie E (2009)

\section{INDEX}

operation Expertise (EX)

Index géographique : Poitou-Charentes, Charente-Maritime (17), Fouras

Index chronologique : âge du Bronze, Empire romain, ép. contemporaine, Néolithique, Moyen Âge

Thèmes : cimetière paroissial, édifice, église, enclos, inhumation, mer, occupation du sol, remblai, sépulture

\section{AUTEURS}

\section{BASTIEN GISSINGER}

CG de l'Aisne 